\title{
Sickle cell anemia in Brazil: personal, medical and endodontic patterns
}

\section{Shirlene Barbosa Pimentel FERREIRA ${ }^{(a)}$ \\ Warley Luciano Fonseca TAVARES(a) \\ Marco Aurélio Camargo da ROSA ${ }^{(a)}$ \\ Luciana Carla Neves de BRITO(b) \\ Leda Quércia VIEIRA(c) \\ Hercílio MARTELLI JÚNIOR(d) \\ Antônio Paulino RIBEIRO \\ SOBRINHO(a)}

(a) Universidade Federal de Minas Gerais UFMG, School of Dentistry, Department of Restorative Dentistry, Belo Horizonte, MG, Brazil.

(b) Fundação Universidade de Itaúna - FUI, School of Dentistry, Itaúna, MG, Brazil.

(c) Universidade Federal de Minas Gerais - UFMG, Biological Sciences Institute, Department of Immunology and Biochemistry, Belo Horizonte, MG, Brazil.

(d) Universidade Estadual de Minas Gerais - UNIMONTES, Montes Claros School of Dentistry, Montes Claros, MG, Brazil.

Declaration of Interests: The authors certify that they have no commercial or associative interest that represents a conflict of interest in connection with the manuscript.

\section{Corresponding Author:}

Warley Luciano Fonseca Tavares

E-mail:warleyt@hotmail.com

DOI: 10.1590/1807-3107BOR-2016.vol30.0060

Submitted: Aug 16, 2015

Accepted for publication: Nov 22, 2015

Last revision: Feb 24, 2016
Abstract: Sickle cell anemia (SCA) is the most prevalent genetic disease worldwide. Recurrent vaso-occlusive infarcts predispose SCA patients to infections, which are the primary causes of morbidly and mortality. This study aimed to evaluate the relationship between SCA and endodontic diseases. Personal information, medical data (hematological indices, virologic testing, blood transfusions, medications received, splenectomy) and information on the need for endodontic treatment were obtained from SCA patients who were registered and followed up by the Fundação Hemominas, Minas Gerais, Brazil.These data were compared with the need for root canal treatment in SCA patients. One hundred eight patients comprised the studied population, and the rate of the need for endodontic therapy was $10.2 \%$. Among the medical data, a significant difference was observed for eosinophil $(p=0.045)$ counts and atypical lymphocyte counts $(p=0.036)$ when the groups (with and without the need for endodontic treatment) were compared. Statistical relevance was observed when comparing the patients with and without the need for root canal therapy concerned eosinophil counts and atypical lymphocyte counts. The differences in statistical medical data, observed between the groups suggest that both parameters are naturally connected to the stimulation of the immune system that can occur in the presence of root canal infections and that can be harmful to SCA individuals.

Keywords: Anemia, Sickle Cell; Endodontics; Hemoglobinopathies.

\section{Introduction}

Sickle cell anemia (SCA) is a heterogeneous clinical condition characterised by episodes of vaso-occlusion and infectious events. ${ }^{1}$ SCA is the most prevalent genetic disease worldwide, ${ }^{2}$ as well as in Brazil. ${ }^{3}$ This hemoglobinopathy is caused by a mutation in the beta globulin gene of the hemoglobin molecule, resulting in the production of abnormal hemoglobin, called hemoglobin $S$ $(\mathrm{HbS})$. The presence of hemoglobin S in homozygosis ( $\mathrm{HbSHbS}$ ) triggers the formation of polymers when it is deoxygenated, leading to erythrocyte rigidity, loosening of the biconcave discoid shape of erythrocytes and changing the cells' shape into a sickle shape, followed by membrane damage and hemolysis. As a consequence of this occurrence, the sickle-shaped red blood cells obstruct the capillaries, restricting blood flow to organs, which results in ischemia, pain, and often tissue damage. ${ }^{1}$ Vaso-occlusive events can lead to complications, such as avascular necrosis of the bones, osteopenia, osteoporosis, retinal infarction, stroke, pulmonary hypertension and skin ulcerations. ${ }^{4}$ 
Recurrent vaso-occlusive infarcts predispose SCA patients to infections, which are the most common complications and the primary causes of morbidly and mortality in SCA patients. ${ }^{5,6,7,8}$ Studies have shown an association between hematological factors and pathologic alterations in SCA..$^{910}$ The elevated white blood cell counts in sickle cell disease have been reported as being able to predict morbid events in patients with the disease. ${ }^{11}$ Moreover, during persistently low oxygen tension, these cells are recognised by the reticuloendothelial system and are destroyed. The red blood cells of individuals with normal hemoglobin $(\mathrm{HbA})$ survive approximately 120 days, while the red blood cells of Hbs individuals survive only between 15 and 25 days. ${ }^{12}$ The accumulation of these distorted cells is responsible for vaso-occlusion and most SCA-related disorders.

Oral complications have been described in SCA patients. Those that have been recorded include: mandibular osteomyelitis, anesthesia of the mandibular nerve, and asymptomatic pulpal necrosis. Osteomyelitis occurs several hundred times more frequently in SCA patients than in the rest of the population and that up to $29 \%$ of SCA patients experience at least one episode of osteomyelitis during their lifetime. . $3,44,15,16,17^{-1}$ Permanent neuropathies affecting the inferior dental nerve after an SCA have been reported and resulted in persistant anesthesia for up to 24 months. ${ }^{18,19}$

The occurrence of asymptomatic pulp necrosis has been described in clinically intact permanent teeth in patients with SCA. It has been associated to vaso-occlusion of the pulp microcirculation..$^{12,20,21}$ In this regard, the prevalence of pulp necrosis was reported to be 8.33 times higher $\mathrm{HbS}$ individuals compared to $\mathrm{HbA}$ individuals. ${ }^{12}$ Sickle cells have also been identified in teeth with a history of repeated episodes of pulpal pain. ${ }^{20}$ This finding indicates that not only the mandibular bone structure is affected by the sickling crises, but the microcirculation of the pulp is compromised. ${ }^{22}$

Knowing the benefits of a health policy on SCA population, especially on its oral conditions, might lead to the implementation of strategies to promote the health of SCA patients. The aim of this study was to compare the personal information and need for root canal treatment of SCA patients with their medical and hematological data at the time of initial dental presentation (first appointment).

\section{Methodology}

A descriptive and cross-sectional study was conducted from October 2010 to August 2012. Data were obtained from 108 evaluated patients with confirmed diagnoses of SCA (HbSS genotype), who were registered and followed up by the Fundação Hemominas, Regional Montes Claros, Minas Gerais, Brazil. Personal information (sex and age) and information on the need for endodontic treatment were obtained from the patients during dental appointments. Medical data (hematological indices, serologic testing, blood transfusions, medications received, splenectomy) were obtained from medical records. Patients were excluded from this study if they had taken antibiotics within the 3 months prior to the initiation of endodontic therapy.The criteria adopted to determine the need for endodontic treatment were based on clinical and radiographic analyses, along with pulp vitality tests (Vitality Scanner ${ }^{\mathrm{TM}}$, Sybron Endo, Orange, USA). ${ }^{23}$ Correlations among the collected data were calculated. This study was approved by the Research Ethics Committees of the Fundação Hemominas (ETIC 283/10), Universidade Estadual de Montes Claros - UNIMONTES (ETIC 1848/10) and Universidade Federal de Minas Gerais - UFMG (ETIC 203/10).

\section{Statistical analysis}

After data collection, statistical analysis was performed using SPSS statistical software for Windows (SPSS Inc., version 17.0, Chicago, USA). Descriptive analyses were performed to verify the patients' characteristics and the prevalence of oral and systemic conditions. Bivariate analysis was performed to examine the relationship between the needs for endodontic treatment and for blood cells. The significant differences between categorical variables were examined with the Chi-square test and with Fischer's exact test. Statistical significance was defined as a p-value of 0.05 or less.

\section{Results}

\section{Patient characteristics}

One hundred eight patients $(n=108)$ were included in this study. A total of 61 female patients (56.5\%) and 47 male patients (43.5\%), 5 to 59 years old (median 
age, 32 years) comprised the eligible individuals. The patients who needed to receive endodontic care corresponded to $10.2 \%(n=11)$ of the study subjects.

\section{Blood transfusions}

Among all of the patients, $68.5 \%$ received blood transfusions. Of the patients who required root canal therapy, $63.6 \%$ were submitted to blood transfusions, whereas $69.1 \%$ of the patients without the need for endodontic treatment were not transfused. When the two groups (with and without the need for endodontic therapy) were compared, no statistically significant differences were observed $(p=0.739)$.

\section{Serologic testing}

Of the eligible population, positive serologic test results for syphilis $(0.9 \%)$, Chagas disease $(3.7 \%)$, hepatitis (anti-HBc) (3.7\%), hepatitis (anti-HCV) $(2.8 \%)$ and HTLV I/II $(0.9 \%)$ were detected. However, in the group of patients who needed root canal treatment, the HTLV I/II test results were negative (Table 1).

\section{SCA regimen}

Folic acid and hydroxyurea were the most commonly prescribed agents for the SCA patients in this study. Of the eligible population, $99.1 \%$ received folic acid therapy, and $21.3 \%$ received hydroxyurea therapy. All of the patients who required endodontic treatment received folic acid therapy, and in the same group, 9.1\% received hydroxyurea therapy. When the two groups (with and without the need for endodontic treatment)

Table 1. Description of positive serologic testing in $\mathrm{HbSS}$ patients with and without the need for endodontic treatment.

\begin{tabular}{lccc}
\hline \multirow{2}{*}{ Serologic testing } & HbSS & \multicolumn{2}{c}{ Endodontic treatment (\%) } \\
\cline { 3 - 4 } & patients (\%) & Yes & No \\
\hline Syphilis & 0.9 & 9.0 & 0.00 \\
Chagas disease & 3.7 & 9.0 & 27.30 \\
Hepatitis (Hbs Ag) & 0.0 & 0.0 & 0.00 \\
Hepatitis (Anti-HBc) & 3.7 & 9.0 & 27.30 \\
Hepatitis (Anti-HCV) & 2.8 & 9.0 & 18.18 \\
HIV 1 & 0.0 & 0.0 & 0.00 \\
HIV 2 & 0.0 & 0.0 & 0.00 \\
HTLV I/II & 0.9 & 0.0 & 9.09 \\
\hline
\end{tabular}

HbSS: Homozygous sickle cell disease. were compared, no significant differences were observed for folic acid administration $(p=1.000)$ or hydroxyurea administration $(p=0.451)$. Table 2 shows the medications, including different drugs, according to the regimen and the proportion of patients who received each therapy.

\section{Splenectomy}

Splenectomised patients represented $1.9 \%$ of the SCA patients included in this study. Of the patients who required root canal treatment, $0 \%$ was submitted to splenectomy, and $2.1 \%$ of the patients in the group without the need for root canal treatment were splenectomised. No significant difference was observed when these data were compared between the groups of patients with and without the need for root canal treatment $(p=1.000)$.

\section{Hematological indices}

In this study, $43.5 \%$ of all of the patients presented leucocyte (white blood cells) counts greater than 11,000 cells $/ \mathrm{mm}^{3}$, whereas $56.5 \%$ presented leucocyte counts between 4,000 cells $/ \mathrm{mm}^{3}$ and 11,000 cells $/ \mathrm{mm}^{3}$. In addition, $99.1 \%$ of SCA patients presented basophil counts between 0 cells $/ \mathrm{mm}^{3}$ and 200 cells $/ \mathrm{mm}^{3}$ (Table 3). The eosinophil counts were greater than 500 cells $/ \mathrm{mm}^{3}$ for $20.4 \%$ of the population and for $45.5 \%$ and $17.5 \%$ of the patients with and without

Table 2. Percentage of patients according to each prescribed medication.

\begin{tabular}{lcc}
\hline Percentage/Number & Medication \\
\hline SCA suffers $(n=108)$ & 77 & Folic acid \\
\hline 11.3 & 20 & Folic acid, hydroxyurea \\
18.5 & 1 & Folic acid, captopril \\
0.9 & 1 & Folic acid, caverdilol \\
0.9 & 1 & Folic acid, captopril, caverdilol \\
0.9 & 1 & Folic acid, captopril, furosemida \\
0.9 & 1 & Folic acid, exiade \\
0.9 & 1 & Folic acid, fenitoína \\
0.9 & 1 & Folic acid, hidroxyurea, exjade \\
0.9 & 1 & Folic acid, hidroxyurea, paracetamol \\
0.9 & 1 & Folic acid, paracetamol \\
0.9 & 1 & Folic acid, vitamin D \\
0.9 & 1 & Carbamazepin, captopril, hidroxyurea \\
0.9 & 1 &
\end{tabular}

SCA: Sickle cell anemia. 
the need for root canal therapy, respectively. The SCA patients presented banded neutrophil counts $<700$ cells $/ \mathrm{mm}^{3}(100 \%)$ and segmented neutrophils count between 1,800 cells $/ \mathrm{mm}^{3}$ and 7,000 cells $/ \mathrm{mm}^{3}$ (69.4\%). In the groups that required and did not require endodontic therapy, $81.8 \%$ and $81.4 \%$ exhibited lymphocyte counts between 1,000 cells $/ \mathrm{mm}^{3}$ and 4,500 cells $/ \mathrm{mm}^{3}$, respectively. Concerning atypical lymphocyte counts, $45.5 \%$ and $16.5 \%$, respectively, of the patients who required or did not require endodontic treatment presented counts $>1 \mathrm{cell} / \mathrm{mm}^{3}$. The percentages of SCA patients who presented metamyelocyte counts and myelocyte counts of 0 cells $/ \mathrm{mm}^{3}$ were $98.1 \%$ and $100 \%$, respectively. When the white blood cell counts were compared between the patients with and without the need for root canal therapy, a statistically significant difference was detected only for the eosinophil $(p=0.045)$ counts and atypical lymphocyte counts $(\mathrm{p}=0.036)$.

Table 4 shows the erythrocytes counts: they were $<4.0 \times 10^{6}$ cells $/ \mathrm{mm}^{3}$ for female subjects and $<4.5 \times 10^{6}$ cells $/ \mathrm{mm}^{3}$ for male patients in all of the patients in the group requiring endodontic treatment and in $86.6 \%$ of the group not requiring endodontic care. Hemoglobin concentrations $<12.8(\mathrm{~g} / \mathrm{dL})$ for male patients and $<11.6(\mathrm{~g} / \mathrm{dL})$ for female patients was observed in $100 \%$ and $95.9 \%$ of the patients with and without the requirement for endodontic therapy, respectively. In this study, the mean corpuscular volume
(MCV) levels were $>98 \%$ in $26.8 \%$ of the patients who did not require endodontic therapy and in $9.1 \%$ of the patients who required root canal treatment. Among all of the patients of this study, $19.4 \%$ showed mean corpuscular hemoglobin (MCH) less than 27 (pg). Of those patients who did not require endodontic treatment, 19.6\% presented MCH less than 27 (pg), and $35.1 \%$ presented $\mathrm{MCH}$ greater $34(\mathrm{pg})$. However, in $18.2 \%$ of patients with the need for root canal therapy, $\mathrm{MCH}$ was greater than $34(\mathrm{pg})$. The mean corpuscular haemoglobin concentration $(\mathrm{MCHC})$ was $<31.5(\mathrm{~g} / \mathrm{dL})$ for $15.7 \%$ of the eligible patients. An MCHC $<31.5(\mathrm{~g} / \mathrm{dL})$ was observed in $9.1 \%$ and $16.5 \%$ of the groups with and without the need for endodontic treatment, respectively. Herein, $96.3 \%$ of the patients presented reticulocyte counts $>2.3 \%$. Regarding the need or not for endodontic treatment, $100 \%$ and $95.9 \%$ of these patients presented reticulocyte counts $>2.3 \%$, respectively. The majority of the SCA patients (96.3\%) presented hematocrit $<36 \%$ for female patients and $<38 \%$ for male patients. In the groups with and without the need for endodontic treatment, $100 \%$ and $95.9 \%$ of the patients, respectively, presented hematocrit $<36 \%$. No significant differences were observed when comparing the groups with and without the need for endodontic treatment, taking into consideration the red blood cell counts $(\mathrm{p}>0.05)$.

Finally, platelet counts $>360 \times 10^{3}$ cells $/ \mathrm{mm}^{3}$ were observed in $72.7 \%$ and $62.9 \%$ of those patients who required and did not require root canal treatment,

Table 3. White blood cell scores in HbSS patients with and without the need for endodontic treatment

\begin{tabular}{|c|c|c|c|c|c|c|c|c|}
\hline \multirow{3}{*}{$\begin{array}{l}\text { White blood cells } \\
\text { (cells } / \mathrm{mm}^{3} \text { ) }\end{array}$} & \multicolumn{8}{|c|}{ Endodontic treatment } \\
\hline & \multicolumn{4}{|c|}{ Yes } & \multicolumn{4}{|c|}{ No } \\
\hline & Mean & Median & SD & Min/Max & Mean & Median & SD & Min/Max \\
\hline Basophil & 82.82 & 69.00 & 119.765 & $0 / 402$ & 49.98 & 0.00 & 73.856 & $0 / 348$ \\
\hline Eosinophil & 570.73 & 163.00 & 576.756 & $691 / 582$ & 601.91 & 360.00 & 826.732 & $0 / 5989$ \\
\hline Metamielocyte & 0.00 & 0.00 & 0.000 & $0 / 0$ & 0.00 & 0.00 & 0.000 & $0 / 0$ \\
\hline Banded neutrophil & 128.55 & 0.00 & 244.068 & $0 / 815$ & 102.38 & 40.00 & 133.385 & $0 / 656$ \\
\hline Segmented neutrophil & 4251.18 & 3955.00 & 1492.078 & $1789 / 7335$ & 5195.24 & 4880.00 & 2352.760 & $345 / 12672$ \\
\hline Limphocyłe & 4543.45 & 4154.00 & 1480.140 & $2760 / 7342$ & 4723.71 & 4715.00 & 1687.800 & $763 / 8855$ \\
\hline Monocyte & 635.64 & 472.00 & 361.384 & $180 / 1340$ & 581.55 & 578.00 & 382.405 & $0 / 2132$ \\
\hline Mielocyte & 0.00 & 0.00 & 0.000 & $0 / 0$ & 0.00 & 0.00 & 0.000 & $0 / 0$ \\
\hline Atypical limphocyte & 59.75 & 40.00 & 67.724 & $0 / 163$ & 29.78 & 0.00 & 70.081 & $0 / 374$ \\
\hline
\end{tabular}

SD: standard deviation; Min: minimum; Max: maximum. 
Table 4. Hematological scores in HbSS patients with and without the need for endodontic treatment.

\begin{tabular}{|c|c|c|c|c|c|c|c|c|}
\hline \multirow{3}{*}{ Hematological data } & \multicolumn{8}{|c|}{ Endodontic treatment } \\
\hline & \multicolumn{4}{|c|}{ Yes } & \multicolumn{4}{|c|}{ No } \\
\hline & Mean & Median & SD & Min/Max & Mean & Median & SD & Min/Max \\
\hline Erythrocyte $\left(\times 10^{6} / \mathrm{mm}^{3}\right)$ & 2.448 & 2.600 & 0.4006 & $2.0 / 3.1$ & 8.484 & 8.300 & 17.182 & $6.0 / 15.7$ \\
\hline Hemoglobin (g/dL) & 7.400 & 7.300 & 13.3870 & $5.2 / 9.2$ & 25.779 & 24.800 & 59.009 & $16.5 / 47.0$ \\
\hline Hematocrit (\%) & 22.545 & 22.400 & 32.2350 & 18.0/28.0 & 91.852 & 92.200 & 114.578 & $70.2 / 122.7$ \\
\hline$M C V(f L)$ & 92.491 & 92.600 & 124.0370 & $74.6 / 122.0$ & 30.733 & 31.200 & 51.010 & $20.4 / 44.2$ \\
\hline $\mathrm{MCH}(\mathrm{pg})$ & 31.000 & 31.800 & 49.6510 & $23.8 / 41.6$ & 33.259 & 33.200 & 22.544 & $28.9 / 41.4$ \\
\hline$M C H C(g / d L)$ & 33.482 & 33.500 & 15.1510 & $31.3 / 36.6$ & 8.656 & 7.000 & 70.266 & $1.0 / 55.0$ \\
\hline Reticulocyte (\%) & 9.318 & 10.000 & 33.3370 & $5.0 / 14.0$ & 429.610 & 414.000 & 148.083 & $117.0 / 960.0$ \\
\hline Platelet $\left(\times 10^{3} / \mathrm{mm}^{3}\right)$ & 434.180 & 434.000 & 114.7070 & $204.0 / 620.0$ & 8.484 & 8.300 & 17.182 & $6.0 / 15.7$ \\
\hline
\end{tabular}

MCV: mean corpuscular volume; $\mathrm{MCH}$ : Mean corpuscular hemoglobin; MCHC: mean corpuscular hemoglobin concentration; SD: standard deviation; Min: minimum; Max: maximum.

respectively. None $(0 \%)$ of the patients with the need for endodontic treatment exhibited platelets counts $<140 \times 10^{3} \mathrm{cells} / \mathrm{mm}^{3}$. No significant difference $(\mathrm{p}=0.769)$ was observed when the two groups (with and without the need for endodontic treatment) were compared.

\section{Discussion}

A recent study attempted to assess the epidemiological aspects of root canal diseases, defining the prevalence of the need for endodontic care in a given population. ${ }^{23}$ This study reported a rate of $14.5 \%$ of $\mathrm{HIV}$-infected patients requiring endodontic treatment. ${ }^{23}$

A previous study analyzed the Pulp sensitivity in a SCA Turkey population in an area with high prevalence of heterozygote patients with SCA. Overall, pulp necrosis occurred with pathoses in $6 \%$ of those teeth. ${ }^{21}$ In this study, we detected a rate of $10.2 \%$ of SCA patients requiring endodontic therapy. This rate could reflect lower budgets and less policy support for dental programs in public dental health services, which offer basic dental assistance mostly to lower socioeconomic groups in Brazil. Moreover, it is important to note that the true prevalence of the need for endodontic treatment in SCA patients in Brazil would only be possible to determine via multicentre studies performed in different states.

Sickle cell anemia affects between $0.1 \%$ and $0.3 \%$ of Afro-Brazilian-descended people. ${ }^{24}$ In 2001 in the state of Minas Gerais, 87 of 128,326 newborns were carriers of hemoglobin S (HbS), 46 of whom had the disease. ${ }^{25}$ The Fundação Hemominas, Regional Montes Claros, Minas Gerais, Brazil, is responsible for monitoring SCA patients referred from different cities, and this centre is located in northern of the state of Minas Gerais.

The prognosis of people living with SCA depends on the SCA regimen. Herein, the most commonly prescribed agents were folic acid and hydroxyurea. The hydroxyurea provides therapeutic benefit through multiple mechanisms of action. ${ }^{26}$ The efficacy of hydroxyurea in the treatment of SCA-related disease has generally been attributed to its ability to increase fetal hemoglobin $(\alpha 2 \gamma 2)$ and consequently to decrease hemoglobin $\mathrm{S}(\mathrm{Hbs})$ as a compensatory mechanism that prevents the polymerisation of intercellular hemoglobin. Hydroxyurea administration leads to greater survival of erythrocytes, resulting in a decrease in the frequency and severity of vaso-occlusive episodes and diminishing the severe course of SCA, thus bringing clinical benefits. ${ }^{27}$ Folic acid reduces the risk of endothelial damage. Its prescription is justified by its improvement of the production and maturation of red blood cells. ${ }^{28,29}$ All of the SCA patients in this study who required endodontic treatment were under folic acid regimens, but only one of them was taking hydroxyurea. When the two groups (with and without the need for endodontic treatment) were compared, no significant difference was observed for the two agents. Conversely, another 
study ${ }^{12}$ reported that $\mathrm{HbS}$ individuals presented more pulp necrosis in clinically intact permanent tooth than $\mathrm{HbA}$ subjects, and this rate remained significant after folic acid prescriptions were taken into account.

Blood transfusions were required in $68.5 \%$ of the patients as an ordinary procedure in the management of the SCA..$^{30}$ Continual transfusions of red blood cells greatly decrease disease severity. Their use is supported by transfusions decreasing the percentage of $\mathrm{HbS}$, suppressing $\mathrm{HbS}$ synthesis, and reducing hemolysis. ${ }^{5,31}$ However, blood transfusions are considered a risk factor for infections..$^{30}$ Today, the exclusion of high-risk donors, along with increases in technology, has reduced during procedures of the risk of the transmission of diseases, such as viral hepatitis and human immunodeficiency viruses (HIV I and HIV II), in northern Europe and the United States. ${ }^{31}$ In this study, positive serology for syphilis, Chagas disease, hepatitis (anti-HBc), hepatitis (anti-HCV) and human lymphotropic virus (HTLV) was assayed for the eligible individuals. However, in the group of patients who required endodontic treatment, the latter test (HTLV I/II) was negative.

Neutrophilia is a useful marker of infection in many clinical settings, as well as in $\mathrm{SCA},{ }^{78}$ because the prevalence and intensity of neutrophilia are higher in SCA patients with bacterial infections than in those without infections. Additionally, neutrophilia in SCA individuals can be accompanied by eosinopoenia. ${ }^{78}$ Our findings showed that only one SCA patient presented with neutrophilia. Despite the significant difference $(p=0.045)$ observed in the eosinophil counts when the groups with and without the need for endodontic treatment were compared, eosinopoenia was not observed among the eligible patients.

Leucocytosis is a risk factor for hemorrhagic stroke in children and adults, as well as a risk factor for acute chest syndrome and early death. Increased white blood cell counts can predict morbid events in sickle cell disease. ${ }^{11}$ Leucocytosis was observed in $43.5 \%$ of the SCA patients included in this study. Moreover, it was observed in $45.4 \%$ and $27.3 \%$ of the patients in the groups with and without the need for endodontic treatment, respectively.

In SCA patients, immune cells, such as monocytes, neutrophils and endothelial cells, are in a permanently activated status, ${ }_{11}^{11}$ which result in the production of immune mediators as cytokines and chemokines. A recent study from our research group demonstrated that teeth with periapical lesions from SCA individuals presented prone proinflammatory ability, expressing IL-1, TNF- $\alpha$, and IL-17A at a significantly higher level compared to healthy teeth from control patients. ${ }^{32}$

In this study, $96.3 \%$ of the SCA patients presented hematocrit $<39 \%$ among male patients and $<36 \%$ among female patients. High hematocrit is a risk factor for vaso-occlusive crises, acute chest syndrome, and avascular necrosis,,$^{30}$ and it has been suggested that hemoglobin level plays a role in the deformability of sickled cells. ${ }^{9}$ Accordingly to previous results in SCA patients, ${ }^{1} 88 \%$ of eligible patients presented red blood cells $<4,500\left(\times 10^{6} / \mathrm{mm}^{3}\right)$ cells and $<4,000\left(\times 10^{6} / \mathrm{mm}^{3}\right)$ cells for male and female patients, respectively.

Platelets contribute to vascular inflammation by activating neutrophils in SCA patients, in addition to their pro-coagulant role. ${ }^{33}$ Increased platelet count activation has been recognised in the vasculopathy of SCA disease. ${ }^{34}$ Abnormalities in blood rheology and platelet dysfunction might play a role in the pathogenesis of multiple organ failure in septic patients by reducing microvascular blood flow. ${ }^{35}$ Red blood cell aggregation properties are likely to be involved in the pathophysiology of sickle cell disease: the increased shear forces needed to disperse red blood cell aggregates may disturb blood flow, especially at the microcirculatory level, since red blood cell are only able to pass through narrow capillaries as single cells rather than as aggregates. ${ }^{36}$ Platelet counts $>360 \times 103$ cells $/ \mathrm{mm}^{3}$ were observed in $72.7 \%$ of those patients who required root canal treatment in the present study. The deleterious effect of reduced blood flow and perfusion in the capillary pulp microcirculation may have contributed to pulp necrosis.

\section{Conclusion}

This study assessed the need for endodontic treatment in a controlled population of SCA patients assisted at a public dental health service in Brazil, and it attempted to determine the relationships between SCA and endodontic diseases. Despite providing knowledge of the epidemiological root canal requirements of 
the SCA population, the unique statistical relevance observed when comparing the patients with and without the need for root canal therapy concerned eosinophil counts and atypical lymphocyte counts. Both parameters are naturally connected to the stimulation of the immune system that can occur in the presence of root canal infections and that can be harmful to SCA individuals. Hence, this study reinforces the necessity for government polices to improve dental health service for these individuals.

\section{References}

1. Kato GJ, Hebbel RP, Steinberg MH, Gladwin MT. Vasculopathy in sickle cell disease: Biology, pathophysiology, genetics, translational medicine, and new research directions. Am J Hematol. 2009;84(9):618-25. doi:10.1002/ajh.21475

2. World Health Organization. Sickle cell anemia: report of secretariat. 59a World of Health Assembly [Internet]. [place unknown]: WHO; 2006 [cited 2013 Jan 5]. Available from: http//www.who.int/gh/ebwha/pdf_files/WHA59_9-en.pdf

3. Loureiro MM, Rozenfeld S. Epidemiology of sickle cell disease hospital admissions in Brazil. Rev Saude Publica. 2005;39(6):943-9. doi:10.1590/S0034-89102005000600012

4. Miller RG, Segal JB, Ashar BH, Leung S, Ahmed S, Siddique $\mathrm{S}$, et al. High prevalence and correlates of low bone mineral density in young adults with sickle cell disease. Am J Hematol. 2006;81(4):236-41. doi:10.1002/ajh.20541

5. Rees DC, Williams TN, Gladwin MT. Sickle-cell disease. Lancet. 2010;376(9757):2018-31. doi:10.1016/S0140-6736(10)61029-X

6. Booth C, Inusa B, Obaro SK. Infection in sickle cell disease: a review. Int J Infect Dis. 2010;14(1):e2-12. doi: 10.1016/j.ijid.2009.03.010

7. Ahmed SG, Uraka AJ. Eosinopenia as a marker of infection in patients with sickle cell anaemia: a preliminary report. Int J Biomed Health Sci. 2010;6(1):57-61.

8. Ahmed SG . The role of Infection in the pathogenesis of vaso-oclusive crisis in patients with sickle cell disease [Internet]. 2011 [cited 2012 Dec 10];3(1):e2011028. doi:10.4084/MJHID.2011.028. Available from: http://www. mjhid.org/article/view/8471

9. Hayes RJ, Condon PI, Serjeant GR. Haematological factors associated with proliferative retinopathy in homozygous sickle cell disease. Br J Ophthalmol. 1981;65(1):29-35. doi:10.1136/bjo.65.1.29

10. Miller ST, Sleeper LA, Pegelow CH, Enos LE, Wang WC, Weiner SJ, et al. Prediction of adverse outcomes in children with sickle cell disease. N Engl J Med. 2000;342(2):83-9. doi:10.1056/NEJM200001133420203

\section{Acknowledgments}

This work was supported by Fundação de Amparo à Pesquisa do Estado de Minas Gerais - FAPEMIG, Coordenação de Aperfeiçoamento de Pessoal de Nivel Superior - CAPES and Conselho Nacional de Desenvolvimento Científico e Tecnológico - CNPq. The authors wish to thank the post-graduate program at the School of Dentistry of Universidade Federal de Minas Gerais - UFMG. L.Q.V., H.M.J., and A.P.R.S. are CNPq fellows.

11. Jison ML, Munson PJ, Barb JJ, Suffredini AF, Talwar S, Logun, $\mathrm{C}$ et al. Blood mononuclear cell gene expression profiles characterize the oxidant, hemolytic, and inflammatory stress of sickle cell disease. Blood. 2004;104(1):270-80. doi:10.1182/blood-2003-08-2760

12. Costa CP, Thomaz EB, Souza SF. Association between Sickle Cell Anemia and pulp necrosis. J Endod. 2013;39(2):177-81. doi:10.1016/j.joen.2012.10.024

13. Golding JS. The bone changes in sickle cell anaemia. Ann R Coll Surg Engl. 1956;19(5):296-315.

14. Engh CA, Hughes JL, Abrams RC, Bowerman JW. Osteomyelitis in the patient with sickle-cell disease. J Bone Joint Surg Am. 1971;53(1):1-15.

15. Ryan MD. Osteomyelitis associated with sickle-cell anemia. Report of a case. Oral Surg Oral Med Oral Pathol. 1971;31(6):754-9. doi:10.1016/0030-4220(71)90128-9

16. Patton LL, Brahim JS, Travis WD. Mandibular osteomyelitis in a patient with sickle cell anemia: report of case. J Am Dent Assoc. 1990;121(5):602-4. doi:10.14219/jada.archive.1990.0224

17. Shroyer JV 3rd, Lew D, Abreo F, Unhold GP. Osteomyelitis of the mandible as a result of sickle cell disease. Report and literature review. Oral Surg Oral Med Oral Pathol. 1991;72(1):25-8. doi:10.1016/0030-4220(91)90184-E

18. Friedlander AH, Genser L, Swerdloff M. Mental nerve neuropathy: a complication of sickle-cell crisis. Oral Surg Oral Med Oral Pathol. 1980;49(1):15-7. doi:10.1016/0030-4220(80)90025-0

19. Gregory G, Olujohungbe A. Mandibular nerve neuropathy in sickle cell disease. Local factors. Oral Surg Oral Med Oral Pathol. 1994;77(1):66-9. doi:10.1016/S0030-4220(06)80109-X

20. Andrews CH, England MC Jr, Kemp WB. Sickle cell anemia: an etiological factor in pulpal necrosis. J Endod. 1983;9(6):249-52. doi:10.1016/S0099-2399(86)80023-1 
21. Demirbaş Kaya A, Aktener BO, Ünsal C. Pulpal necrosis with sickle cell anaemia. Int Endod J. 2004;37(9):602-6. doi:10.1111/j.1365-2591.2004.00853.x

22. Ingle J, Taintor JF. Endodontics. 3rd ed. Philadelphia (PA): Lea \& Febiger; 1985. 174 p.

23. Brito LCN, Rosa MAC, Lopes VS, Ferreira EF, Vieira LQ, Ribeiro Sobrinho AP. Brazilian HIV-infected population: assessment of the needs of endodontic treatment in the post-highly active antiretroviral therapy era. J Endod. 2009;35(9):1178-81. doi:10.1016/j.joen.2009.05.004

24. Ramalho AS, Magna LA, Paiva-e-Silva RB. Government Directive MS \# 822/01: unique aspects of hemoglobinopathies for public health in Brazil. Cad Saude Publica. 2003;19(4):1195-9. Portuguese. doi:10.1590/S0102-311X2003000400040

25. Paixão MC, Cunha Ferraz MH, Januário JN, Viana MB, Lima JM. Reliability of isoelectrofocusing for the detection of $\mathrm{Hb} \mathrm{S}, \mathrm{Hb} \mathrm{C}$, and $\mathrm{HB} \mathrm{D}$ in a pioneering population-based program of newborn screening in Brazil. Hemoglobin. 2001;25(3):297-303.

26. Ware RE. How I use hydroxyurea to treat young patients with sickle cell anemia. Blood. 2010;115(26):5300-11. doi:10.1182/blood-2009-04-146852

27. Lanzkron S, Strouse JJ, Wilson R, Beach MC, Haywood C, Park H, et al. Systematic review: hydroxyurea for the treatment of adults with sickle cell disease. Ann Intern Med. 2008;148(12):939-55. doi:10.7326/0003-4819-148-12-200806170-00221

28. van der Dijs FPL, Fokkema MR, Dijck-Brouwer DAJ, Niessink B, van der Wal TIC, Schnog J-JB, et al. Optimization of folic acid, vitamin B(12), and vitamin B(6) supplements in pediatric patients with sickle cell disease. Am J Hematol. 2002;69(4):239-46. doi:10.1002/ajh.10083
29. Hyacinth HI, Gee BE, Hibbert JM. The role of nutrition in sickle cell anemia. Nutr Metab Insights. 2010;3:57-67. doi:10.4137/NMI.S5048

30. Verduzco LA, Nathan DG. Sickle cell disease and stroke. Blood. 2009;114(25):5117-25. doi:10.1182/blood-2009-05-220921

31. Davies SC, Roberts-Harewood M. Blood transfusion in sickle cell disease. Blood Rev. 1997;11(2):57-71.

32. Ferreira SBP, Brito LCN, Oliveira MP, Maciel KF, Martelli Júnior H, Vieira LQ, et al. Periapical cytokine expression in sickle cell disease. J Endod. 2015;41(3):358-62. doi:10.1016/j.joen.2014.11.016

33. Polanowska-Grabowska R, Wallace K, Field JJ, Chen L, Marshall MA, Figler R, et al. P-selectin-mediated platelet-neutrophil aggregate formation activates neutrophils in mouse and human sickle cell disease. Arterioscler Thromb Vasc Biol. 2010;30(12):2392-9. doi:10.1161/ATVBAHA.110.211615

34. Villagra J, Shiva S, Hunter LA, Machado RF, Gladwin MT, Kato GJ. Platelet activation in patients with sickle disease, hemolysis-associated pulmonary hypertension, and nitric oxide scavenging by cell-free hemoglobin. Blood. 2007;110(6):2166-72. doi:10.1182/blood-2006-12-061697

35. Alt E, Amann-Vesti BR, Madl C, Funk G, Koppensteiner R. Platelet aggregation and blood rheology in severe sepsis/septic shock: relation to the Sepsis-related Organ Failure Assessment (SOFA) score. Clin Hemorheol Microcirc. 2004;30(2):107-15.

36. Tripette J, Alexy T, Hardy-Dessources MD, Mougenel D, Beltan E, Chalabi T et al. Red blood cell aggregation, aggregate strength and oxygen transport potential of blood are abnormal in both homozygous sickle cell anemia and sickle-hemoglobin C disease. Haematologica. 2009;94(8):1060-5. doi:10.3324/haematol.2008.00537 